\title{
ACCIÓN, DECISIÓN Y COMPETENCIAS DELIBERATIVAS EN EL PRESUPUESTO PARTICIPATIVO DE PORTO ALEGRE*
}

\author{
ACTION, DECISION MAKING, AND DELIBERATIVE SKILLS \\ CONCERNING THE PARTICIPATORY BUDGET IN PORTO ALEGRE
}

\author{
Luis Emilio Cuenca Botey ${ }^{* *}$
}

\begin{abstract}
RESUMEN
Este artículo describe y analiza lo que es una competencia deliberativa para las personas que participan en el Consejo del Presupuesto Participativo de Porto Alegre. Utilizando las técnicas de la observación etnográfica, se describen los agentes que intervienen en la acción. Así, se logra aportar una comprensión de las dinámicas de la asamblea y se establece un diálogo entre lo que ocurre dentro y fuera de lo que Marc Abélès llama el "lieu du politique".
\end{abstract}

PALABRAS CLAVE: PORTO ALEGRE, BR * DEMOCRACIA * PARTICIPACIÓN COMUNITARIA * PRESUPUESTO $*$ DESARROLLO PARTICIPATIVO

\section{ABSTRACT}

This paper describes and analyzes the deliberative skills of people participating in the Council of the Participatory Budget (COP), the main deliberation council for the participatory democracy in Porto Alegre. Through the ethnographic observation, we are able to describe agents acting in the assembly. Then, we establish a dialogue between the internal and external events of what Marc Abélès called "lieu du politique".

KEY WORDS: PORTO ALEGRE, BR * DEMOCRACY * COMMUNITY PARTICIPATION * BUDGET * PARTICIPATORY DEVELOPMENT

El presente trabajo es el fruto de la investigación "Participando, articulando, cobrando... Une compréhension du Budget Participatif de Porto Alegre au travers des trajectoires sociales des dirigeants." (Una comprensión del Presupuesto Participativo de Porto Alegre a través de las trayectorias sociales de sus dirigentes) [Tesis de Maestría en Ciencias Sociales con especialidad en Estudios
Comparativos del Desarrollo], Ecole des Hautes Etudes en Sciences Sociales, bajo la dirección de Afranio Garcia.

** Centre de Recherche sur le Brésil Contemporain (CRBC).

luisemilio.cuenca@gmail.com 
La experiencia de democracia participativa en torno al diseño $y$ ejecución del presupuesto municipal de la ciudad de Porto Alegre, capital del estado de Rio Grande del Sur (RGS), en el sur del Brasil, ha sido objeto de mucho interés por parte de intelectuales, militantes $y$ diseñadores de políticas pública ${ }^{1}$. Esta iniciativa, se inscribe en un contexto determinado por la democratización del Brasil, a partir de la década de 1980, que se caracteriza por el auge de los movimientos sociales, el surgimiento de nuevos partidos políticos, $y$ de "nuevas" formas de practicar la política y de incluir, en la esfera pública, la voz de sectores de la población tradicionalmente excluidos.

La investigación académica sobre esas nuevas formas de practicar la política, y especialmente sobre el Presupuesto Participativo de Porto Alegre ${ }^{2}$ (РPPOA) ${ }^{3}$, ha puesto el énfasis

Esta experiencia es considerada una best practice por parte del Banco Mundial y de UNHABITAT. En los últimos años se transformó en un modelo de gestión municipal al nivel tanto nacional como internacional. El Foro Social Mundial y el movimiento llamado "Altermundialista" jugaron un papel importante en la circulación internacional del dispositivo.

El PPPOA es un mecanismo de participación que nació en Porto Alegre, capital del Estado de Río Grande del Sur, Brasil. Cuando el Partido de los Trabajadores llegó al poder en esta ciudad, en el contexto de la democratización de finales de los 80 , se comenzaron a aplicar formas de participación política innovadoras en un intento de redefinición de las relaciones entre el Estado y la sociedad civil. El PPPOA, es un mecanismo en el cual los habitantes de la ciudad pueden participar para elaborar el proyecto de ley presupuestaria de la ciudad. Para estos efectos se crea lo que los actores llaman «el ciclo de participación» que constituye las diferentes etapas de la participación/decisión dentro del dispositivo. Este ciclo se extiende de marzo a enero de cada año. El mecanismo divide la ciudad en 16 regiones (hoy en día 17), cada una con una asamblea plenaria y un foro de delegados. A partir del gobierno Genro (1992-1996), para poder ampliar los horizontes del dispositivo y luchar contra el localismo de las reivindicaciones, se crean las temáticas. Se trata de foros de participación por tema cuya delimitación territorial es la ciudad como un todo. En la actualidad existen 6 asambleas temáticas: circulación y transporte, cultura, educación, en dilucidar su aporte en la construcción de una sociedad democrática. Las preguntas y problemáticas que esta literatura coloca como prioritarias son concomitantes de este contexto político, en el cual la academia y la sociedad en general, reinventan las formas de relación entre el Estado y la sociedad civil ${ }^{4}$.

Los textos de referencia sobre la experiencia de PPPOA contienen preocupaciones que se orientan en ese sentido. Santos (2003) se interesa en las condiciones de emergencia de una esfera pública autónoma. Navarro (1996) reflexiona sobre las condiciones de difusión del modelo del PPPOA en otras municipalidades y cuestiona la autonomía real del dispositivo constatando prácticas de "neo clientelismo" por parte del Partido de los Trabajadores (PT) (Navarro, 2003). Por otro lado, Avritzer (2003: 13) analiza en qué medida esas experiencias representan una profundización de la democracia en Brasil. Kunrath (2003) estudia las condiciones que permiten o favorecen los procesos de acción colectiva que desembocan en la creación de este tipo de mecanismo de participación. Fedozzi (2001: 95) discute la existencia de una relación entre el PPPOA y el surgimiento de la ciudadanía.

desarrollo económico y tributación, organización de la ciudad y Asistencia Social.

La participación en el dispositivo define las prioridades de inversión de la ciudad y las reglas de distribución de las inversiones así como las inversiones más concretas. Por ejemplo, se deciden los montos globales que la ciudad invertirá en asfalto, los montos por región de este mismo rubro $y$ las calles específicas que se financiarán en cada región.

El PPPOA se convirtió en un modelo de gestión municipal participativa para las corrientes llamadas de nueva izquierda, $y$ una «best practice» para los organismos internaciones como UNHABITAT y el Banco Mundial. Para tener un detalle de la historia del PPPOA véase (Kunrath, 2001) y (Cuenca, 2007). Para entender el funcionamiento y las reglas del mecanismo véase (Santos, 2003), (Dias, 2002) y (Cuenca, 2007).

3 De ahora en adelante me referiré por medio de las siglas.

4 Para una discusión detallada del lugar que la literatura dominante sobre el PPPOA en los debates de la intelligentsia brasileña referirse a (Cuenca, 2007). 
Otros ángulos de estudio y otras preguntas han aparecido en los últimos años. Dias (2002) estudia el impacto del PPPOA en la política municipal de Porto Alegre (POA). Damo (2006) problematiza el significado de la participación en las asambleas a través de la observación etnográfica. Coradini (2004) analiza las relaciones entre los mecanismos de participación y las modalidades de militancia política que presuponen.

Este artículo se propone dilucidar las condiciones que un actor requiere para poder imponerse en esta arena de participación. Con este objetivo, se efectúa una socio-etnografía de los procesos de decisión y deliberación que tienen lugar en el Presupuesto Participativo de Porto Alegre (PPPOA). Se trata de comprender el proceso de formación de voluntades, (Manin, 1985) que se concretiza en la determinación y asignación de una parte importante del presupuesto de inversiones de la capital gaucha. La investigación se orienta hacia una perspectiva comprensiva, se apoya en los testimonios de los participantes y en observaciones etnográficas ${ }^{5}$.

La puesta en escena del fenómeno político "pone en espectáculo el universo del cual (el poder) proviene $y$ del que asegura su permanencia” (Abélès, 1997: 247), en consecuencia, se impone una descripción analítica del lieu du politique ${ }^{6}$, para entender mejor el funcionamiento de la asamblea del Consejo del Presupuesto Participativo (COP) ${ }^{7}$, lugar de deli-

El trabajo de campo que da sustento a este texto fue efectuado entre finales de junio e inicios de setiembre del 2006. Este mismo fue la base de mi tesis de Maestría en «Estudios Comparativos del Desarrollo» en la Ecole des Hautes Etudes en Sciences Sociales. Para más información sobre este trabajo veáse (Cuenca, 2007).

Abélès, a partir de la observación de las asambleas tradicionales, concluye que en estas se construye espacial y simbólicamente un lugar distinto, que el autor llamará lieu du politique (Abélès, 1997: 250). Traducido literalmente al español diríamos lugar de lo político, sin embargo como no encontramos una expresión más adecuada en nuestra lengua, decidimos, conservar el vocablo francés.

$7 \quad$ Existen tres tipos de asamblea dentro del PPPOA. Las plenarias, son las asambleas de inicios de ciclo beración principal dentro del dispositivo de participación en el cual sólo los consejeros ${ }^{8}$ tienen voz y voto.

En la primera parte de este artículo se describe la estructura, el funcionamiento $y$ la representación simbólica de los espacios sociales en conflicto, así como las lógicas de la acción que estructuran estos últimos. Se intenta demostrar que dentro del Consejo del Presupuesto Participativo, la «performance» deliberativa, constituye únicamente, la parte visible de un proceso de decisión/deliberación, que responde a elementos que no aparecen en el espacio público.

En la segunda parte, se explicitan los elementos constitutivos de una competencia deliberativa, entendida como la capacidad de un actor para tomar la palabra $y$ tener un efecto importante en la toma de decisiones. El PPPOA se presenta como un espacio de socialización política, en el cual los actores aprenden a deliberar y a emplear la práctica participativa, conforme a los valores $y$ a las limitaciones impuestas por el dispositivo.

de participación, en las cuales los participantes votan las prioriodades de la ciudad y eligen a los delegados $y$ a los consejeros. Tienen lugar una vez al año y son las que sirven de base para contar el número de participantes por año en el dispositivo. En el momento de nuestra observación existían 16 plenarias regionales $y$ los foros de delegados, se reúnen una vez por semana y su función principal es la de priorizar las infraestructuras que serán financiadas con los montos asignados a la región o a la temática. El Consejo del Presupuesto Participativo (COP) es el foro de deliberación más importante de todos. Allí se discute directamente con el ejecutivo municipal, el proyecto de ley presupuestaria de la ciudad. Los consejeros son representantes de las comunidades, y es por esta razón que son el objeto de nuestro estudio.

8 El PPPOA de 2006, año en el cual efectuamos nuestro trabajo de campo, estaba dividido en 16 regiones y 8 asambleas temáticas. En cada una de ellas se eligen dos consejeros titulares y dos suplentes durante su respectiva asamblea plenaria. Los consejeros integran después el COP y dirigen los foros de delegados. Para ser delegado se necesita llegar con 10 personas a la asamblea plenaria. Para ser consejero se necesita hacer una papeleta que presente 4 nombres. La papeleta más votada elige un consejero cada $25 \%$ de los votos. El resto serán para la papeleta derrotada. 


\section{EL «LIEU DU POLITIQUE»}

El Consejo del Presupuesto Participativo (COP) se encuentra integrado por dos consejeros titulares $y$ dos suplentes por cada región $y$ asamblea temática del PPPOA, así como por un titular y un suplente del SIMPA (Sindicato de Empleados de la Municipalidad de POA) y un titular y un suplente de la UAMPA ${ }^{9}$. Según el artículo primero del reglamento interno vigente en el 2006, el cop es un órgano de participación directa de la comunidad que tiene como misión la planificación, la proposición y la deliberación sobre los ingresos y los gastos del presupuesto de la municipalidad (PMPA, 2006: 2).

El cOP se reúne todos los martes y algunos jueves desde las 18 horas hasta las 21 horas en la sala 10 del mercado público ${ }^{10}$ de Porto Alegre (POA). Esta sala es un lugar animado, ruidoso por dentro y por fuera, rodeado de restaurantes que ofrecen conciertos o partidos de fútbol, los famosos jogo de futebol, tan perjudiciales para la asistencia de algunos miembros. El mercado público, es una de las joyas arquitectónicas de la ciudad ${ }^{11}$. Actualmente, es un espacio donde se encuentran casi todas las personas provenientes de las diferentes categorías sociales de la ciudad. El mercado se encuentra frente al edificio principal de la municipalidad, al lado del «Rio Guaiba». A sus costados se encuentran las paradas de numerosas líneas de autobuses, que unen el centro rico y urbanizado con la periferia de la ciudad.

Los consejeros aprovechan la proximidad espacial con el ejecutivo municipal para establecer una relación particular, lo que denominan, en sus propias palabras, el governo ${ }^{12}$. La imagen 1 nos permite observar la proximidad entre el COP y el ejecutivo municipal. La imagen 2

\section{IMAGEN 1}

\section{PERÍMETRO DE MOVILIDAD DE LOS CONSEJEROS EN EL CENTRO DE PODER}

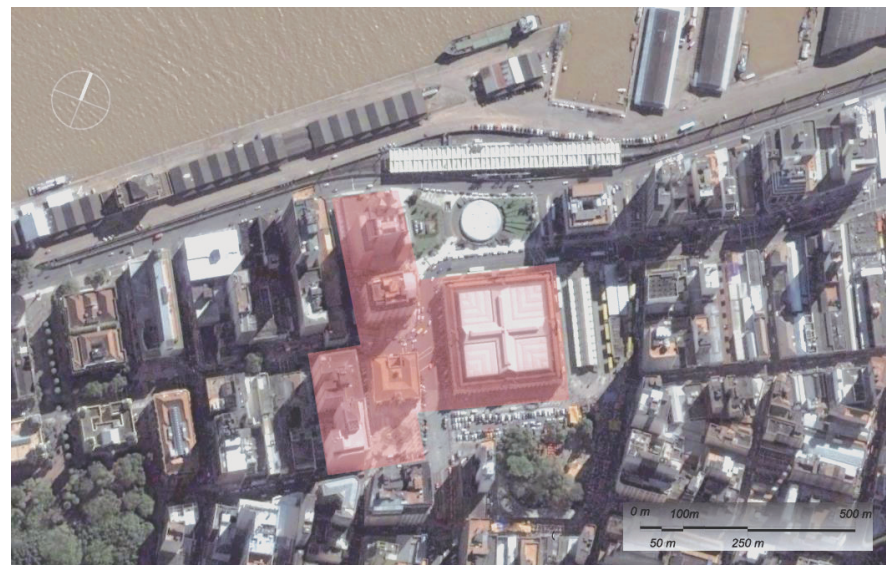

Fuente: Cuenca, 2007: 95.

9 l'União das Associaçoes de Moradores de Porto Alegre (Unión de Asociaciones de Barrio de Porto Alegre-UAMPA) fue creada en 1983 para agrupar al sector combativo del movimiento comunitario (Baierle, 1992: 156). Esta organización es la primera en reivindicar el acceso a las decisiones presupuestarias de la municipalidad.

10 La sala 10 del mercado público es un lugar reservado para las reuniones de los diferentes movimientos sociales de la ciudad. Fue creada por decisión del COP durante la renovación del mercado público, la cual fue decidida también por los consejeros.
11 Inaugurado en 1869, el mercado público jugó un papel importante en la dinámica económica de POA, puesto que alli llegaban los productos del interior de Rio Grande do Sul.

12 Las palabras en itálico son aquellas utilizadas por los actores del proceso. La restitución de las palabras que los actores utilizan para comprender el mundo, metodología básica del análisis etnográfico, es una parte esencial para probar lo que se afirma en este artículo. 


\section{IMAGEN 2}

\section{SITUACIÓN ESPACIAL DE LA MUNICIPALIDAD, LA CÂMARA Y EL COP}

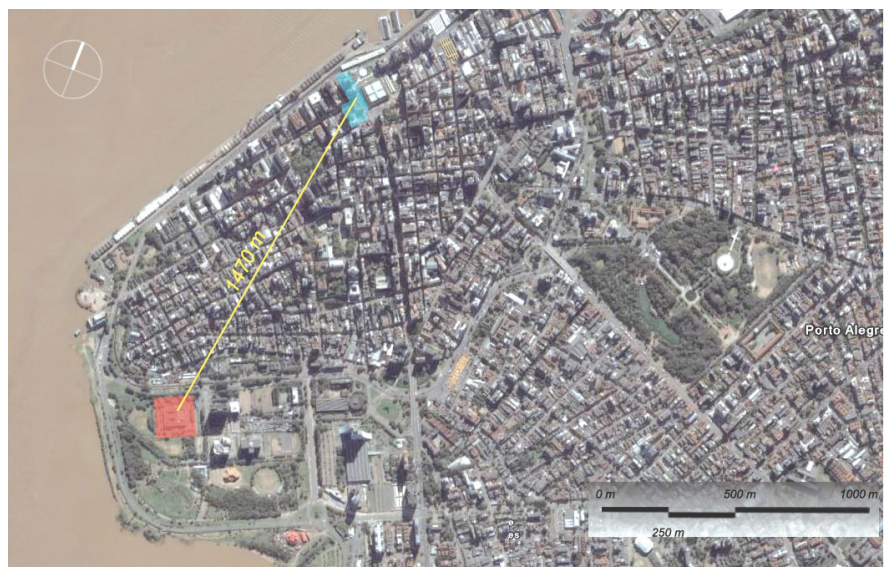

Fuente: Cuenca, 2007: 67.

compara la situación espacial de la «Câmara dos Vereadores» —regidores_ ${ }^{13}$ (en rojo) con respecto al ejecutivo municipal y al cop (en azul).

La superficie en rojo de la imagen 1, corresponde al área de circulación de un consejero cuando este se encuentra en el centro del poder. El edificio blanco con una cruz en el techo es el mercado público. Los otros edificios

En Brasil, desde la Constitución de 1988, cada nivel de la división administrativa del territorio cuenta con tres poderes. Es el caso del nivel federal, estatal y municipal. El poder legislativo al nivel local lo ejercen los «vereadores», regidores municipales que, en el caso de una ciudad del tamaño y la importancia de POA, cuentan con recursos importantes $y$ con un poder significativo sobre las comunidades representadas. Cuando el PT llegó al poder en 1988, era ampliamente minoritario dentro del legislativo municipal, que tiene la potestad de aprobar, cambiar o rechazar, el proyecto de ley presupuestario de la ciudad. En este marco, la concretización de un poder «participativo» fue también una de las estrategias para sortear la dificultad de gobernar la ciudad con el legislativo en contra. Dándole al PPPOA la prerrogativa de elaborar el proyecto de ley presupuestario, se hacía más difícil para los regidores municipales, modificar el presupuesto. Para poder entender el conflicto y la competencia institucional que se establece entre el PPPOA y el COP en contra del legislativo municipal, véase (Dias, 2002). en rojo son las diferentes oficinas de la municipalidad donde los consejeros realizan numerosos trámites, reclamos, articulaciones y otras tareas propias de su función. El perímetro de movilidad es de 782 metros si sumamos todos los lados de la superficie en rojo de la imagen 1. Como lo señala Bourdieu,

La proximidad en el espacio físico permite a la proximidad en el espacio social, producir todos sus efectos, facilitando, o favoreciendo la acumulación de capital social y, más precisamente, permitiendo el aprovechamiento continuo de los encuentros fortuitos $y$ previsibles asegurados por la presencia en los lugares bien frecuentados $^{14}$ (Bourdieu, 1993: 165).

Esto sugiere que en las trayectorias sociales de los consejeros la relación con el ejecutivo y la administración municipal adquiere un carácter particular ${ }^{15}$.

\footnotetext{
14 Traducción propia.

15 Para un análisis de las trayectorias sociales de las personas que alguna vez ocuparon el puesto de consejeros así como de las condiciones sociales de posibilidad para ser consejero, veáse (Cuenca, 2008) y (Cuenca, 2007).
} 
LA SALA 10 DEL MERCADO PÚBLICO:

ESTRUCTURA DEL «LIEU DU POLITIQUE»

En la sala 10 de reuniones del mercado la disposición de los asientos asemeja la de un salón de clases, no es de orden circular. Al frente se encuentra una tarima, donde se ubica la mesa. En esta se sientan los miembros de la coordinación, integrada por los consejeros elegidos en el seno del COP para dirigir la reunión, y los miembros del ejecutivo municipal, o governo. Entre estos últimos, siempre hay alguien que ocupa el puesto de director del PPPOA, un puesto político ligado al secretario de la «Secretaria da Governança». Esta secretaría se encarga de responder a los reclamos y quejas de los consejeros.

En la mesa, se sientan aquellos que no son Povo o su equivalente, comunidade. Esto es válido incluso para los consejeros. Al frente se encuentran unas cien sillas, donde se sienta el Povo ${ }^{16}$ o comunidade. A la izquierda de la mesa, se ubica la intérprete que se comunica con la comunidade sorda y la persona que toma el acta de la reunión. Luego se encuentra el micrófono y para poder acceder a él, los participantes deben inscribirse y esperar su turno, en el cual se dirigen al público durante tres minutos cronometrados.

La zona donde se encuentra el micrófono, constituye el espacio para la realización de la mayor parte de las «performances» de deliberación. Se utiliza para efectuar, esencialmente, tres funciones. Cobrar, cuando se trata de reclamar, acusar o denunciar al governo; elogiar cuando se reconocen las buenas acciones del governo o, de otras comunidades o, de sus propios pares y socializar cuando se comparten informaciones de diversa índole. Lo primero que

Durante nuestro trabajo de campo, era normal ver a los consejeros sentados en la «mesa» desplazarse a la sala durante algunas votaciones o reclamos para ser «povo». El movimiento iba acompañado de la frase «agora eu sou povo». El mismo movimiento con el mismo comentario fue observado en los foros de delegados. se socializa son las preocupaciones y los asuntos dolorosos, los problemas para llevar a cabo los proyectos de las comunidades y las actividades que estas realizan. Además, se informa sobre el desarrollo de seminarios de formación, actividades militantes $y$ sindicales, de las ONG e informaciones provenientes de otros foros de la ciudad, donde el cop tiene derecho a enviar representantes. Las informaciones socializadas pueden poseer fines estratégicos, para desnudar las intenciones de algunos o favorecer las de otros.

La estructura de una reunión del cop es semejante a otros tipos de reunión o asambleas que se producen en el dispositivo. Los primeros 30 minutos corresponden a los informes, informaciones generales, cuyo objetivo es el de socializar. Después comienza la pauta, es decir la agenda prevista para la reunión, que depende siempre de los miembros del gobierno que se encuentran presentes ese día y de las obligaciones propias del ciclo de participación.

Todas las intervenciones están limitadas a tres minutos, cronometrados con un teléfono celular o un reloj, por uno de los miembros de la coordinación. Hablar más de tres minutos es un privilegio reservado a aquellos que tocan los temas «más importantes» o a quienes, por su estatus, tienen un derecho implícito de sobrepasar el tiempo de palabra. Algunas intervenciones consiguen que alguno de los que espera su turno les ceda parte de su tiempo, lo que subraya la importancia de lo que se expresa.

El coP funciona como un lugar de control y seducción entre el ejecutivo municipal y los representantes de las comunidades. Aunque los consejeros niegan la presencia de la política en el mecanismo, es evidente que ella se encuentra mediando en todo momento, lo que no implica que los que pertenecen a un partido del governo no se atrevan a criticarlo. Las relaciones son más complejas, no se pueden asumir racionalidades pre-establecidas a los representantes, según su afiliación partidaria. Esto implicaría desconocer las múltiples dimensiones en las cuales estos representantes 
circulan, adquieren compromisos, desarrollan sentimientos y colocan las expectativas de un futuro mejor para sus representados y para ellos mismos.

Lo que está en juego no es sólo el dinero, a verba, para una inversión, a obra. Es también el honor, el tiempo dedicado, la familia y todo lo que se coloca sobre la balanza para determinar los resultados obtenidos durante largos años de participación. Eso incluye emociones, sensaciones, estados de ánimo, valores y metas.

\section{EL ESPACIO SIMBÓLICO: REPRESENTACIÓN DE LOS ESPACIOS SOCIALES EN CONFLICTO ${ }^{17}$}

La puesta en escena del fenómeno político que tiene lugar en el COP, constituye una representación simbólica, que le da substancia a las diferentes dimensiones de la acción política. Este lugar y su estructuración, expresan el reflejo de las dinámicas sociales reales dentro de los espacios sociales que se relacionan dentro de este foro de deliberación. Sin embargo, la representación simbólica tiene como vocación simplificar la realidad, $y$ otorgarle un sentido político que esconde la complejidad de las relaciones que se crean en ese juego de poder. Lo que se representa y lo que no se representa toma sentido a través de la observación de lo que sucede fuera del «lieu du politique».

En el esquema que construimos, es posible constatar dos espacios que se con-

En el esquema p. 140, leánse las palabras que aparecen en francés, en el sentido de las agujas de un reloj de la manera siguiente: «Intérprete para los sordos», «Micrófono», «Coordinación», «Espacio exterior situado dentro del mercado público y utilizado para las articulaciones con el governo o entre consejeros», "Centro de poder compuesto por tres o cuatro personas que siempre ocupan este lugar en la sala», «ejemplo de una articulación acompañada de un desplazamiento en el sentido de la flecha». "Lugar de mucha circulación de personas». «Desplazamiento que permite un cambio de estatus». (Traducción del autor). frontan frente a frente: o Povo (el pueblo) que es el equivalente de la comunidade y el Governo que se encuentra en la mesa, con los otros representantes de las comunidades que conforman la coordinación del cop. Estos últimos, cuando no están en la mesa se consideran Povo.

Esta comunidad, o povo, es un medio de constitución de lo que es común a todos, a pesar de que cada uno de ellos representa una comunidad diferente. Es la puesta en escena de una unión, que se encuentra atravesada por una heterogeneidad, que representa a grupos diferentes, ligados a organizaciones interesadas por la disputa de las retribuciones simbólicas ${ }^{18}$, que se obtienen mediante la participación. Estas organizaciones muy pocas veces poseen intereses convergentes.

Esta estructura es la puesta en escena de una relación vertical, asimétrica, en la cual el governo ocupa un pequeño lugar del espacio físico disponible, pero es el actor principal del proceso. La asimetría es necesaria para la sobrevivencia del mecanismo, ya que la inversión de roles constituye un principio fundacional. La importancia de la confrontación y la distinción de los espacios se expresa en las reglas del dispositivo, ya que los miembros del governo no tienen derecho a voto $y$ no pueden ocupar un puesto de consejero.

El sentido de la confrontación se observa a través del significado de la palabra cobrar, que es la actividad principal de un consejero. Se trata de reclamar al governo y de que les reclamen aquellos que se encuentran más abajo en la pirámide participativa. El consejero cobra o governo, y la comunidade cobra al consejero. Se constituye, de esta manera, una cadena vertical desde abajo hacia arriba.

Las dos posiciones son distintas, se definen unas con respecto a otras, pero no pueden sobreponerse. Una de las frases que escuchamos más a menudo durante nuestro

18

Sobre el papel de las retribuciones simbólicas en el compromiso político véase (Gaxie, 1977) y (Gaxie, 2005). Para un análisis del rol de las retribuciones en las trayectorias militantes de los consejeros veáse (Cuenca, 2007) y (Cuenca, 2008). 
ESQUEMA 1

DINÁMICAS, ESTRUCTURAS Y SIGNIFICADOS DEL ESPACIO EN UN COP

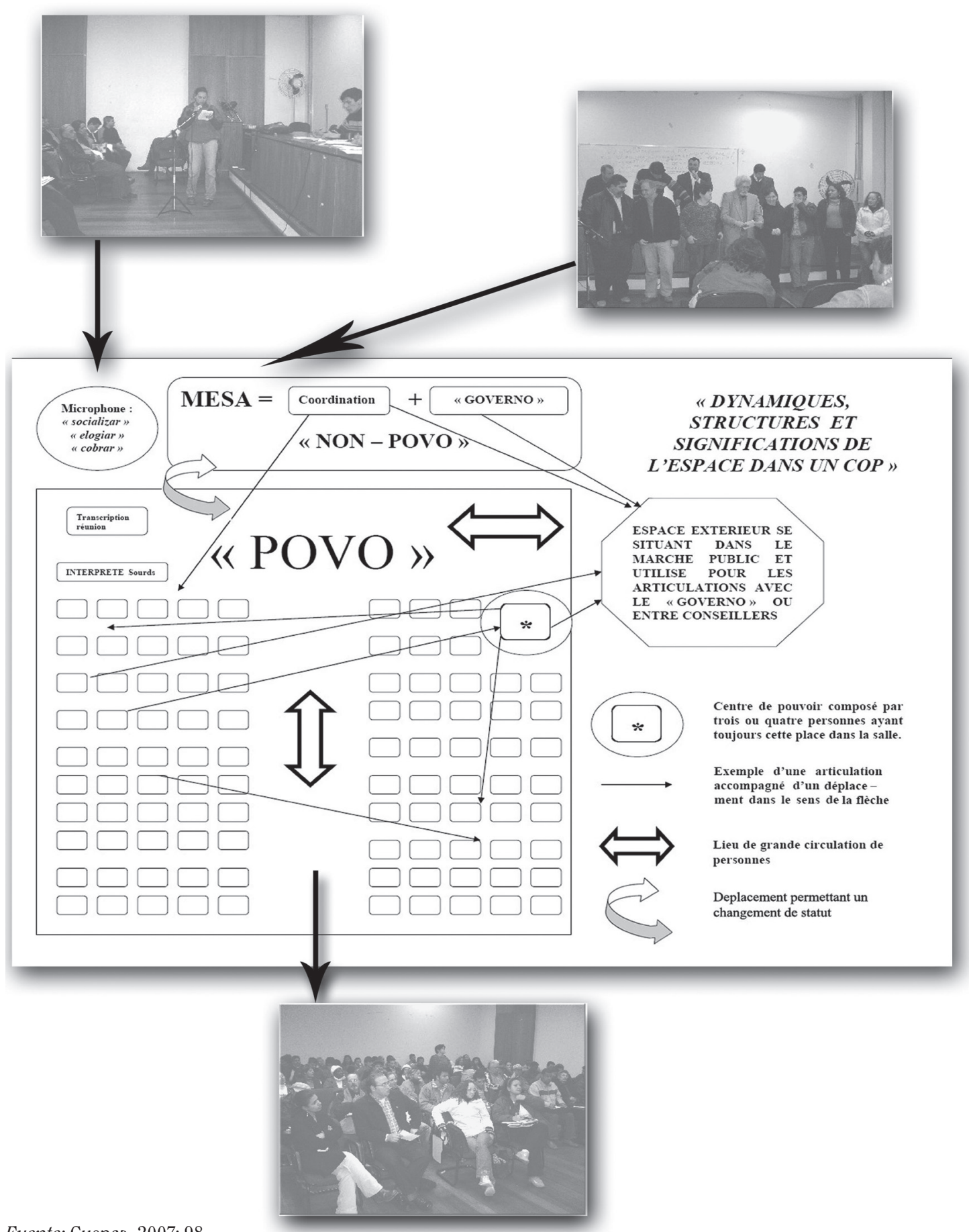

Fuente: Cuenca, 2007: 98. 
trabajo de campo fue "Voce não pode ser governo e comunidade» ${ }^{19}$. Ocupar dos posiciones es inconcebible en el espacio físico y en el espacio social.

El «lieu du politique» observado de forma dinámica, con los movimientos entre espacios de significación, es también el reflejo de esta proximidad entre espacios sociales distintos que no se pueden sobreponer, pero de los cuales el actor puede servirse para cambiar de posición. La flecha, que muestra el movimiento de cambio de estatus dentro de la sala, cuando un consejero pasa de la mesa al micrófono o al público para convertirse de nuevo en comunidade, es el símbolo de una tensión importante en la vida real de estas personas, quienes muchas veces tienen la «tentación» de abandonar la comunidade para trabajar para el governo. Entonces, se produce un cambio de posición en el espacio social, que ocurre muchas veces, por medio de lo que ellos llaman cooptação, la cooptación, es decir, pasan a ser contratados por el governo o por uno de los partidos del governo.

Este movimiento polémico en el «lieu du politique» y en el espacio social, es concomitante a uno de los aspectos más importantes del dispositivo, que es la proximidad entre consejeros y personalidades políticas de alto rango. La cercanía de los espacios ocupados por los actores puestos en escena, que se traduce en la posibilidad de hacer un movimiento simbólico $y$ real de posición en el «lieu du politique» y en el espacio social, nos permite introducir una dimensión transversal en los espacios, la comunidade y el governo, que es la dimensión de los partidos políticos y de las organizaciones con fines públicos como los sindicatos y las ONG.

$\mathrm{El}$ «lieu du politique» representa las dinámicas políticas en conflicto, pero lo que no se representa es tan importante como lo que está puesto en escena. La política partidaria está oficialmente excluida del dispositivo, puesto que ella no se adapta a la idea de comunidad, la que vehicula la pureza, la homogeneidad y la unión. Los partidos, cuyos principios esenciales de funcionamiento son la división y la competencia, no

«Usted no puede ser al mismo tiempo «gobierno»y «comunidad»». tienen un lugar oficial dentro del mecanismo. Sin embargo, en el estudio que efectuamos sobre las trayectorias sociales de los consejeros (Cuenca, 2007: 119-158), estas organizaciones aparecen como los principales vectores para que los consejeros cambien de posición dentro del espacio político y social.

$\mathrm{Al}$ igual que en un espectáculo, la «performance» pública se encuentra condicionada por lo que pasa en los camerinos. En el caso del $\mathrm{COP}$, la función de articular es la que permite dar cuenta de los preparativos, para la puesta en escena de la deliberación. La articulação es el movimiento que relaciona a las personas $y$ a los colectivos que participan. Es una palabra que denota la necesaria flexibilidad de los movimientos para hacer frente a una realidad compleja, en vista de cumplir objetivos diversos. Articulando, se establecen alianzas entre consejeros con capacidades de movilización distintas, pero también con el governo, un actor central, a pesar de no acceder al voto.

La necesidad de las articulações muestra que dentro del juego político, ningún actor puede ser hegemónico por sí solo. La constitución de una red de relaciones resulta absolutamente necesaria. El adjetivo articulado define un conjunto de características valorizadas como las condiciones necesarias para conquistar as obras (obtener inversiones). Se trata de un adjetivo que describe a una persona astuta, con capacidades para circular en los diferentes espacios sociales que entran en relación dentro del PPPOA, $y$ con posibilidades de poner esta capacidad al servicio de una estrategia, para lograr objetivos colectivos o particulares, dentro del dispositivo.

Articular es un movimiento hacia todos los lados del tablero, pragmático, $y$ valorizado como acción, pero no como ideal. Un consejero jamás justificaría en público sus acciones o se distinguiría diciendo «eu sou articulado», son los otros consejeros quienes lo califican de esa manera en privado. Se trata de un adjetivo que se expresa en tercera persona, «ele, ela, é articulado (a)». Por esta razón, las articulações se producen, en su gran mayoría, hacia el exterior del «lieu du politique». Ellas negocian las diferentes estrategias que determinan las performances deliberativas de los actores en conflicto. 
¿CÚAL ES LA COMPETENCIA DELIBERATIVA QUE PERMITE IMPONERSE EN ESTA PUESTA EN ESCENA?

La deliberación dentro del COP se encuentra muy influenciada por los elementos que se señalan a continuación. El tiempo de palabra limitado, la puesta en escena de una relación vertical y conflictiva entre el povo y el governo, el contenido de lo que se discute y el lugar de la deliberación, son algunos de los factores que explican una aparente ausencia de los debates «racionales», donde el mejor argumento se impone ${ }^{20}$.

El pensar esta arena de deliberación como un espacio de teatralización del fenómeno político, donde una gran parte de las «performances» se construyen en función de lo que sucede «afuera» del «lieu du politique», posibilita entender mejor lo que significa ser competente en este contexto. Las competencias que permiten articular, cambiar de posición en el espacio - estar en la coordinación por ejemplo-y ser exitoso convenciendo a los demás, son las que determinan la rentabilidad de una «performance» deliberativa $y$ la necesidad de recurrir a esta herramienta por parte de los actores.

Para imponerse dentro del COP hace falta algo más que el manejo de un discurso «sabio» o carismático, sobre el tratamiento de los problemas. Se necesita que los actores intercambien los diversos capitales sociales de que disponen. La omnipresencia de la articulação constituye una prueba de que la competencia deliberativa, depende de la constitución de lo que llamaremos, el capital militante.

La noción de capital militante es esencial para comprender lo que se encuentra en juego. Se refiere a las "habilidades adquiridas en particular gracias a propiedades sociales que permiten desenvolverse, con éxito variable, en un espacio que está lejos de ser homogéneo"

El paradigma de la democracia deliberativa supone que si el proceso de toma de decisión es el bueno, es posible llegar a una decisión en la cual el mejor argumento es el que se impone. Para una discusión sobre el paradigma de la democracia deliberativa, véase (Manin, 1985) y (Blondiaux y Sintomer, 2002).
(Poupeau, Matonti; 2004: 11) ${ }^{21}$. Estas habilidades son movilizadas por los actores para adaptarse a las dinámicas del proceso y aprender de estas últimas. El capital militante es el resultado de la suma de los capitales sociales, culturales y económicos que los actores disponen, $y$ de los aprendizajes durante la participación, para afrontar los desafíos de la acción dentro del PPPOA. La formación de un capital militante se produce durante el proceso de socialización política, que tiene lugar dentro del dispositivo.

\section{EL PPPOA Y EL APRENDIZAJE DE MODALIDADES DE COMPROMISO POLÍTICO}

Los consejeros requieren, para deliberar dentro del PPPOA, adquirir e interiorizar una concepción de la participación y un «saber hacer» adaptado a las normas del dispositivo. En efecto, el sentirse autorizado para tomar la palabra y deliberar a cualquier nivel del PPPOA, así como provocar un efecto en la toma de decisiones constituyen capacidades producto de un proceso de aprendizaje. Este último responde a un proceso de socialización política, en el cual los actores que tienen éxito, son aquellos que aprenden a deliberar utilizando los códigos, las reglas y las palabras aceptadas como legítimas, así como los modos de compromiso político que permiten movilizar los recursos necesarios y tener un mayor peso en el proceso de decisión.

\section{CONCEPCIÓN DE LA PARTICIPACIÓN: ¿EL UNIVERSALISMO DEL INDIVIDUO CIUDADANO?}

Avritzer demuestra que, el dispositivo del PPPOA es el producto de tres proposiciones iniciales, que implica tres tipos de lógicas deliberativas (Avritzer, 2002). El dispositivo se levanta alrededor de algunos principios esenciales contenidos en sus fundamentos ideológicos, una mezcla de las influencias de las Comunidades Eclesiásticas de Base (CEBS), de concepciones políticas de la izquierda del PT y de un espíritu gestionario, muy influenciado

21 Traducción propia. 
por el pensamiento y la práctica de Ubiratán de Souza ${ }^{22}$.

El mecanismo está guiado por una concepción de la participación que es la del individuo-ciudadano e implica un deber de participación universal (Coradini, 2004). Esta concepción se aplica en las grandes asambleas plenarias y se mezcla con el principio piramidal inspirado en los soviets, puesto que en esa época, una parte del PT creía en la posibilidad de formar un consejo municipal de trabajadores. El espíritu gestionario y la voluntad redistributiva se concretizan en las reglas de distribución de recursos que favorecen a los territorios más pobres y a las comunidades que participan más ${ }^{23}$.

El significado del verbo participar, para los actores, permite comprender mejor la traducción de las concepciones ideológicas en la práctica política. Se trata de un verbo que describe la acción más importante que se desarrolla en el dispositivo. Todos pueden $y$ deben participar. Es la condición de existencia del mecanismo y es lo que permite demandar, formular las demandas de inversión. De ahí que la frase que más se escucha sea: «Orçamento Participativo não é Orçamento Demandativo» ${ }^{24}$

Considerado como el padre del PPPOA, Bira estuvo encargado de la dirección del GAPLAN, oficina de planificación de la municipalidad, durante la consolidación del dispositivo en la primera gestión de Tarso Genro (1992/1996). Economista de formación, estuvo exilado en el Chile de Allende donde dirigió una empresa nacionalizada bajo el modelo de la autogestión. Hoy en día es un experto en «presupuestos participativos» y ofrece la receta a diversos organismos y gobiernos (Venezuela por ejemplo). Actualmente trabaja para el despacho de Raúl Pont, ex-alcalde, diputado estatal en RGS y miembro de la DS, sección de extrema izquierda del PT.

23 Para una descripción de las lógicas de representación y de participación así como del ciclo de participación véase (Gret y Sintomer, 2005) y (Santos, 2003). Para un estudio sobre la redistribución presupuestaria entre las regiones de la ciudad, veáse (Marquetti, 2002).

«El presupuesto participativo no es un presupuesto demandativo». quiere decir que antes de poder demandar, hay que participar. Participar es una acción de larga duración, no tiene término definido e idealmente debería formar parte de la cotidianidad del individuo ciudadano. Entendida como una acción positiva, también denota sacrificio, en consecuencia, el adjetivo participativo posee una distinción particular. Para ser un dirigente, hay que ser participativo, hay que estar siempre presente $y$ disculparse cuando, por alguna razón, no se puede asistir a las reuniones.

Participar es un movimiento horizontal que concierne a todos los actores que, los hace iguales y los distingue a la vez, porque permite aprender una nueva manera de ser ciudadano. La concepción de la participación practicada en el PPPOA no es gestionaria, es más bien política. Esta debe permitir una transformación del individuo en un «sujeto consciente». En el imaginario del PPPOA, el objetivo principal del proceso es la transformación del individuo y del espacio físico.

El PPPOA es un mecanismo que sirve para determinar los lugares en los cuales el espacio físico será transformado y por ende urbanizado. El acceso a un espacio «urbano» pasa por la obra, la inversión que construye la infraestructura que permite el acceso a un espacio digno de llamarse «ciudad». Una obra es una calle, un poste de luz, una cañería, un desagüe, un puente o una casa. La obra es lo que permite urbanizar el espacio vital de las personas, lo que les posibilita trabajar en la ciudad sin tener la vergüenza de llegar con los zapatos llenos de barro. Es la lucha por la urbanización que permite acceder a la urbanidad, cuando se participa en la construcción de la ciudad, se accede a la condición de ciudadano.

Esta concepción de la participación que se expresa en todas las reglas formales e informales del dispositivo, favorece a los grupos e individuos que tienen modalidades de compromiso político que comparten estos códigos $y$ valores. Estas modalidades de compromiso, determinan los modos de legitimación de la autoridad personal. Estas se traducen en prácticas de movilización política compatibles con las reglas del dispositivo. El PPPOA constituye un espacio de socialización política, en el cual 
se debe aprender a comprometerse con modalidades compatibles con el dispositivo para poder ser eficaz en la disputa de los recursos.

\section{EL PPPOA COMO ESPACIO DE APRENDIZAJE DE VALORES Y FORMAS DE EXPRESIÓN}

Las reuniones y asambleas del PPPOA son espacios de deliberación, pero también de aprendizaje. Como lo señala Damo, las asambleas plenarias y los foros de delegados son espacios donde se aprende a formular una demanda con las reglas del dispositivo y donde los actores se apropian del lenguaje técnico que vehicula los valores del dispositivo. Pedir debe remplazarse por demandar, conseguir por conquistar, pressar por priorizar ${ }^{25}$. El aprendizaje de este vocabulario garantiza la interiorización de los valores esenciales del dispositivo (Damo, 2003). Estos valores tienen como objetivo cambiar la relación de los individuos con el Estado, con el fin de acabar con los «ismos», el clientelismo y el coronelismo.

El proceso de aprendizaje se desarrolla en formas diversas. Dentro del PPPOA existen «passeurs», líderes que son a la vez promotores de la participación y educadores de los participantes. De esta manera, se explica que observáramos a antiguos consejeros, participando en los foros de delegados y corrigiendo a los nuevos consejeros. Presentamos a continuación un ejemplo ilustrativo de lo que se señala.

Pedir se refiere a una relación asimétrica en la cual el que pide está en una posición de inferioridad con respecto al que da. Demandar se refiere a una relación simétrica en la cual no se pide, se exigen derechos. Conseguir, denota el hecho de que para satisfacer sus necesidades se necesita «arreglárselas», pedirle favores a terceros, depender del azar. Al contrario, Conquistar muestra como demandar es una acción que necesita ser precedida de la lucha política con el fin de mejorar su situación. Pressar, apurar, tratar de hacer las cosas rápido, es lo contrario de priorizar o jerarquizar. Estas dos palabras muestran la dimensión gestionaria del dispositivo en donde se necesita establecer un orden de prioridades para que sean las necesidades más importantes las que sean atendidas primero.
NÃO TEM QUE DIZER MUITO OBRIGADO! ${ }^{26}$

La «tématica da cultura» del 2006/2007 tenía el honor de haber «renovado» a sus «conselheiros» titulares, con la participación de dos jóvenes miembros de la cultura popular de los barrios periféricos. «El italiano», apodo del representante del movimiento «hip hop» se estrenaba ese día como coordinador de la reunión. Entre sus primeras palabras, agradeció al governo el haber hecho la «promesa» de pagar las deudas que tenía con algunos grupos culturales de los barrios. La consejera 10, antigua consejera de este mismo foro $y$ con una gran experiencia dentro del dispositivo, le explicó firmemente que dentro del PPPOA,

Não tem que dizer muito obrigado! tá aí, ta no livro! Tá demandado! É obrigação! É obrigação! Nós somos cidadãos, nós participamos das coisas... nós somos parceiros! (...) Tá demandado, tá hierarquizado, tá no livro... Tem que pagar! Tem que fazer!!... ${ }^{27}$

Temática de Cultura, 7 de agosto del 2006.

Las personas que saben como demandar se convierten en los vectores de difusión de los valores del dispositivo. Ellos son solicitados por los nuevos miembros para poder aprender las formas correctas de la «performance» deliberativa. Entre los discursos observados, muy a menudo escuchamos a los nuevos participantes disculpándose por sus torpezas, y pidiendo ayuda a los más experimentados para poder aprender a desenvolverse de una manera correcta.

$26 \ll$ «No tiene que decir muchas gracias!»

27 «Usted no tiene que agradecerles! ¡Es una obligación! ¡Es una obligación! Nosotros somos ciudadanos, nosotros participamos... ¡Somos socios! Está demandado, está jerarquizado, está escrito en el plan de inversiones... ¡Tienen que pagar! ¡Tienen que hacer las cosas!» 
Las ONG como CIDADE $^{28}$ realizan talleres de formación a los delegados y consejeros. Durante estas formaciones, ellos interiorizan los valores de la participación, del individuo ciudadano, la solidaridad y la transformación. Todos los itinerarios estudiados muestran como los actores que carecen de una socialización política dentro de las organizaciones que vehiculan estos valores, tienen acceso, gracias a su participación dentro del PPPOA, a una formación militante.

La práctica de las negociaciones políticas constituye un momento privilegiado de aprendizaje. La interacción entre los delegados y los consejeros con el gobierno municipal constituye un factor clave en la adquisición de una práctica militante $y$ en el ejercicio de una deliberación, acorde con los valores del dispositivo. Una de las consejeras entrevistadas comenzó a participar después de su instalación en una vila clandestina. Ella nos explicó lo que sucedió el primer día de su participación dentro del PPPOA, cuando se dirigió al $\mathrm{CROP}^{29}$ para pedir consejo sobre cómo lograr la instalación de agua en sus casas, situadas en uno de los lugares más pobres de la región. El CROP, en lugar de decirle que tenía todo el derecho de ser prioritaria en sus demandas, le dijo: "vocês têm então que ser altruístas, demandar pra fora e não pra dentro no momento..." ${ }^{30}$, palabras que ejemplifican una vez más la concepción de la participación dentro del dispositivo. Además estas palabras muestran el papel de las autoridades municipales en la determinación de los comportamientos y la promoción de algunos valores.

Centro de Assessoria e Estudos Urbanos, ONG fundada en 1987, CIDADE tiene como objetivo la promoción de la participación ciudadana en la gestión de la ciudad. Esta ONG acompaña el PPPOA desde sus inicios ofreciendo formación, consejo e investigación. Su colaboración con nuestro trabajo fue esencial para poder llevar a cabo la investigación que da sustento a este trabajo.

Coordinador Regional del Presupuesto Participativo, puesto político de la municipalidad, muy a menudo ocupado por antiguos consejeros.

30 «Por el momento tienen que ser altruístas, hay que demandar para afuera y no para su propia comunidad».
Este papel del governo se resalta aun más en el momento de realización de nuestro trabajo de campo, puesto que el PT no se encontraba en el ejecutivo municipal. Fue posible observar la incomprensión de los participantes experimentados hacia las modalidades de compromiso político que eran favorecidas por el nuevo equipo municipal, que trataba de introducir otro sistema de distribución de recursos llamado «Governança Solidaria Local» ${ }^{31}, y$ promovía entre los consejeros, modificaciones importantes en las reglas del juego. Entre estos cambios, el más importante era la creación de un nuevo calendario, que marcaba una ruptura con las dinámicas que se describen en este texto.

\section{APRENDIZAJE Y ESTRATEGIAS DE LOS ACTORES}

El encuentro con los «passeurs »y con los agentes del governo, de los partidos políticos $y$ de otras organizaciones políticas, es inevitable cuando los actores comienzan a adquirir un capital militante. La socialización política, por medio de los encuentros con los más experimentados, permite a los nuevos aprender el arte de la articulação. Los experimentados conocen las reglas del dispositivo, tienen relaciones y saben a quién dirigirse según las circunstancias. Los experimentados son participativos y por consiguiente aprendieron a ser articulados,

31 La GSL es un programa de contratos entre el sector público, las empresas y las asociaciones $\mathrm{u}$ organizaciones sin fines de lucro. Tiene como objetivo la generación de proyectos de desarrollo local basados en el voluntariado. Las palabras que más utilizan son «parceria», «capital social», «rede social», «programa», «projeto»... Todas estas palabras provienen de una concepción gestionaria de la participación inspirada en las recetas de organismos como «Cities Alliance». El programa utiliza en su comunicación la imagen de la UNESCO que es uno de los patrocinadores. La palabra «Governança» denota una concepción diferente de la participación en la cuál el sector privado mercantil juega un papel muy importante a través de su «Responsabilidad Social». Este último es un concepto en el cual la empresa se convierte en el centro de una red compleja de relaciones contractuales entre agentes públicos y privados. 
en diferentes niveles. La articulação constituye el movimiento que relaciona a las personas de los diferentes colectivos representados dentro del espacio de participación. Es una palabra que denota la necesidad de efectuar movimientos flexibles, para poder hacer frente a los desafíos de una realidad compleja y obtener la realización de objetivos diversos. Articulando, es la forma en la cual los actores logran hacer alianzas entre consejeros con capacidades de movilización distinta, pero también con los agentes del governo y de la administración municipal, quienes a pesar de no contar con el derecho a voto dentro del COP, constituyen los actores más importantes.

Dos reglas esenciales del dispositivo implican la necesidad de recurrir a la articulação. Se trata del procedimiento de determinación del número de delegados y el voto de las prioridades. Estas reglas son concomitantes a la concepción de la participación que regula el PPPOA. Los criterios pesan en las decisiones finales, están sustentados de tal manera que dentro de un territorio (región o sector de la ciudad), los montos globales asignados a un tipo de inversión dependen de las prioridades escogidas y del apoyo de los delegados del foro regional.

Suponer que todos los delegados son individuos-ciudadanos concientes, con el mismo nivel político, en la escogencia de las obras a priorizar, es desconocer las diferencias en términos de educación, de interés y de grado de integración en las organizaciones políticas de la ciudad, así como las estrategias como representantes y representados de los propios actores. En efecto, los actores no disponen de recursos y disposiciones idénticas a la hora de participar ${ }^{32}$.

Nuestra observación y los testimonios recogidos, sugieren que existen actores centralizadores que deciden, o dan líneas de conducta a los demás actores. Estos actores utilizan pronombres posesivos para hablar de los delegados que los apoyan. Ellos se encargan de la coordinación logística previa a una plenaria $y$, dependiendo del resultado, según la correlación de fuerzas, negocian para favorecer la realización de las

Sobre este aspecto específico veáse (Cuenca, 2007) y (Cuenca, 2008) donde encontrará una discusión sobre las condiciones sociales de posibilidad para convertirse en consejero. obras que interesan a la comunidade, representada por el actor.

La asamblea plenaria representa para las lideranças una prueba decisiva, en la cual se muestra la capacidad para movilizar una importante cantidad de personas, lo que permite obtener delegados y lograr que las prioridades tiendan hacia lo que les interesa. Movilizar personas para que asistan a una asamblea, no es tarea fácil, se necesitan medios de transporte y relaciones. La limitación material es de suma importancia y determina gran parte de la asistencia a las asambleas. Los líderes locales deben aprender a utilizar todo lo que esté a su alcance para movilizar a las personas.

La disputa por los recursos siempre pasa por esta articulações. Los actores desarrollan múltiples estrategias para obtener las prioridades de inversión o el servicio demandado. El juego de articulações es complejo y no responde solamente a cálculos «racionales», ni a lógicas completamente individualistas ni totalmente solidarias, ni mucho menos a la búsqueda de la solución más «racional». Todas las lógicas se mezclan dentro de estas articulações, donde la dinámica colectiva exige negociaciones y donde la construcción de la legitimidad de la deman$d a$, depende de la calidad de la deliberación y de los diferentes juegos estratégicos.

La consejera 2, relata como logró obtener la prioridad que le convenía para que la construcción de su calle (Pavimentaçao) fuese elegida entre las cuatro primeras, puesto que el reglamento prevee que solo las regiones que coloquen esta prioridad tendrán inversiones de este tipo. Ella procedió de la manera siguiente ${ }^{33}$ :

«Fiz aquela que eu falei, a articulação... $\mathrm{Eu}$ ia, conseguia as dez, quinze pessoas da minha rua, que era pouca, perto das cem que iam do Morro. Eu chegava no

En la asamblea plenaria no son las demandas las que se someten a votación. Lo que ella me da aquí es un ejemplo con el cual me explica como convence a la otra persona para votar por la prioridad que le conviene a su demanda. Cómo la prioridad de pavimentación tiene que quedar entre las 4 primeras para poder traer fondos destinados a este tipo de obra, los intercambios entre los demandantes se hacen también en función de estas consideraciones. 
Morro e dizia, "olha vocês tão com cem pessoas, eu to com quinze pessoas...", "áh, mas é muito pouco...", "mas pensa bem, é melhor do que nada." E eu... "o que que tu quer?", "ah, eu quero pavimentação", "bom, eu quero saneamento básico", "vamos fazer troca, tu vota umas vinte/trinta pessoas tua, votam na minha demanda, e os meus quinze vão votar na tua demanda, que que tu acha?, vamos fazer essa troca...", "pimba" ! ela passava.. ${ }^{34}$ Consejera $2^{35}$.

La selección de las prioridades no es la «suma» de las voluntades de los individuos, sino el resultado de un proceso más complejo. Esta escogencia depende de la capacidad de los actores para defender sus demandas con los códigos aceptados, pero también de su capacidad de articulación para negociar con los grupos que se disputan los recursos.

La competencia deliberativa, observada en el contexto donde ella se adquiere, debe ser comprendida como la capacidad del actor a adquirir un capital militante. Esta adquisición se visibiliza cuando el actor practica la modalidad de compromiso político, compatible con las reglas formales e informales del dispositivo.

«Hice aquella de la que te hablé, la articulación... Yo iba y llevaba a diez o quince personas de mi calle, lo que no era nada con respecto a las cien personas que venían del «Morro». Y entonces les decía «vean, ustedes tienen cien personas y yo quince...» «ah pero es poca gente...» «pero piénsalo bien, es mejor que nada...» «¿y qué es lo que quieres ?», «yo quiero pavimentación», «y yo quiero saneamiento básico», "vamos a hacer un trueque, veinte o treinta personas votan por tu demanda y las quince personas mías votan por la tuya, ¿qué te parece? ¿Hacemos este trueque ?» y entonces pasaba!»

Aplicamos la numeración que fue utilizada en (Cuenca, 2007). Esta se debe a razones de conservar el anonimato de los entrevistados el cual fue una de las condiciones pactadas antes de hacer las entrevistas. La numeración refiere a unas fichas que contienen el detalle de la trayectoria de cada uno de los entrevistados. Estas se encuentran en las primeras 20 páginas del anexo de (Cuenca, 2007). Las entrevistas originales están disponibles si se quiere verificar lo que se cita en este texto.
Este capital tiene como base los otros capitales adquiridos por el actor durante su trayectoria, los cuales se refuerzan o se debilitan en el proceso de aprendizaje y socialización política descrito en este texto. La performance deliberativa es sólo uno de los elementos constitutivos de un conjunto de relaciones, estrategias y lógicas de la acción colectiva aquí descritas suscintamente.

\section{CONCLUSIÓN}

El funcionamiento real del juego entre los actores contradice las concepciones ideales que se refieren a una voluntad popular general, conformada por las voluntades de individuos libres, que deciden en función del bien común. La formación de una voluntad general en el seno del PPPOA, aunque resulte de la agregación de votos individuales, no es el resultado de la agregación de las preferencias individuales, tal y como lo demuestra la presencia y la acción de actores centralizadores. Estos últimos utilizan a otros actores dentro del proceso como recursos en función de intereses políticos comunitarios o personales.

La realidad, impregnada por relaciones de intercambio pacíficas y conflictuales, donde los actores centralizan recursos de todo tipo para realizar sus objetivos, los de sus representados y los de los múltiples colectivos donde actúan, nos invita a complejizar la comprensión del proceso de formación de voluntades, que desemboca en las decisiones que construyen la ciudad y la urbanidad de sus habitantes.

La deliberación que tiene lugar en el COP aparece como la expresión «performativa» de la disputa que opone a los diferentes colectivos rivales y como el resultado de un proceso de acción colectiva que no aparece dentro del espacio público, pero que determina lo que pasa en las puesta en escena de este espacio. Los discursos producidos se transforman en recursos estratégicos para estos colectivos y para los actores que los expresan.

\section{BIBLIOGRAFÍA}

Abélès, Marc. "La mise en représentation du politique". Anthropologie du politique. lera edición. Paris: Editorial Armand Collin, 1997. 
Avritzer, Leonardo. "O Orçamento Participativo: As Experiências de Porto Alegre e Belo Horizonte". Sociedade Civil e Espaços Públicos no Brasil. 1era edición. Campinas: Editorial Paz e Terra, 2002.

Bourdieu, Pierre. "Effets de lieu". La misère du monde. lera edición. Paris: Editorial du Seuil, 1993.

Coradini, Odaci. Confrontos entre mecanismos e concepções de "participação" política: os conselhos de desenvolvimento regional e o orçamento participativo estadual no rio grande do sul (19992002). Porto Alegre: sin publicar, 2004.

Cuenca Botey, Luis Emilio. "Participando, articulando, cobrando... Une compréhension du Budget Participatif de Porto Alegre au travers des trajectoires sociales des dirigeants". [Tesis de Maestría en Ciencias Sociales con especialidad en Estudios Comparativos del Desarrollo]. Ecole des Hautes Etudes en Sciences Sociales, Paris, 2007.

. "Trayectorias sociales y construcción de una legitimidad dentro del Presupuesto Participativo de Porto Alegre". Ponencia para el congreso de la Asociación Latinoamericana de Ciencias Políticas. Costa Rica, 2008.

Damo, Arlei. "A peça orçamentaria : os sentidos da participação na politica a partir do OP porto-alegrense". Etnografias da participação, Santa Cruz do Sul. Editorial EDUNISC, 2006: 136-183.

Dias, Marcia. Sob o Signo da Vontade Popular-O Orçamento Participativo e o Dilema da Câmara Municipal de Porto Alegre. Belo Horizonte. lera edición. Rio de Janeiro: Editora UFMG, 2002.

Fedozzi, L. Orçamento Participativo: Reflexoes sobre a experiencia de Porto Alegre. Porto Alegre. Editorial Tomo, 2001.

Gaxie, Daniel. "Economie des Partis et rétributions du militantisme". Revue
Française de Science Politique 27 (1). 1977: 123-154.

. "Rétributions du militantisme et paradoxes de l'action collective". Swiss Political Science Review 11 (1). 2005: 157-188.

Gret, Marion; Sintomer, Yves. Porto Alegre, l'espoir d'une autre démocratie. Paris: Editorial La Découverte, 2005.

Kunrath, Marcelo. "Construção da Participação Popular: Analise comparativa de processos de participação na discussão publica do orçamento em municipios da Região Metropolitana de Porto Alegre". [Tesis de Doctorado en Sociología]. UFRGS. Porto Alegre, 2001.

Manin, B. "Volonté générale ou délibération. Esquisse d'une théorie générale de la délibération politique". Le Débat 33. 1985: 1-20.

Marquetti. A. Participação e redistribução: o Orçamento Participativo em Porto Alegre. In. A inovação democratica no Brasil. São Paulo: Edotorial Cortez, 2003.

Matonti, F., Poupeau, F. Le capital militant, essai de définition. Actes de la recherche en Sciences Sociales 5 (155). 2004: 4-11.

PMPA. "Regimento interno criterios gerais, técnicos e regionais Orçamento Participativo 2006/2007". Porto Alegre: Prefeitura Municipal de Porto Alegre, 2006.

Santos, B. "Orçamento Participativo em Porto Alegre : para uma democracia redistributiva". Democratizar a Democracia: os caminhos da Democracia Participativa. 2da edicion. Rio de Janeiro: Editorial Civilização Brasileira, 2003.

Sintomer, Y., Blondiaux, Y. "L’impératif délibératif". Politix. Revue des sciences sociales du politique 15 (57). 2002: 1735. 